\title{
Phylogenetics and Molecular Divergence of Tilapia Fish (Oreochromis Species) Using Mitochondrial D-Loop and Cytochrome b Regions
}

\author{
Ekerette Emmanuel Ekerette ${ }^{1 *}$, Ekei Victor Ikpeme1, Ogbuagu Ugorji Udensi ${ }^{1}$, \\ Michael Ohiokhuaobo Ozoje ${ }^{2}$, Owoidihe Monday Etukudo ${ }^{1}$, Anthony John Umoyen ${ }^{1}$, \\ Samuel Olutunde Durosaro², Matthew Wheto ${ }^{2}$
}

${ }^{1}$ Department of Genetics and Biotechnology, University of Calabar, Calabar, Nigeria

${ }^{2}$ Department of Animal Breeding and Genetics, Federal University of Agriculture, Abeokuta, Nigeria

Email: *ekemeks4life@yahoo.com

How to cite this paper: Ekerette, E.E., Ikpeme, E.V., Udensi, O.U., Ozoje, M.O., Etukudo, O.M., Umoyen, A.J., Durosaro, S.O. and Wheto, M. (2018) Phylogenetics and Molecular Divergence of Tilapia Fish (Oreochromis Species) Using Mitochondrial D-Loop and Cytochrome b Regions. American Journal of Molecular Biology, 8, 39-57.

https://doi.org/10.4236/ajmb.2018.81004

Received: July 22, 2017

Accepted: December 25, 2017

Published: December 28, 2017

Copyright ( $\odot 2018$ by authors and Scientific Research Publishing Inc. This work is licensed under the Creative Commons Attribution International License (CC BY 4.0).

http://creativecommons.org/licenses/by/4.0/

\begin{abstract}
Understanding the level of genetic diversity in any population is an important requisite towards strategizing measures for conservation and improvement of stocks. This study focused on the assessment of phylogenetics and molecular divergence of tilapia fish species obtained from two populations (Domita in South-South and Odeda in South-West, Nigeria) using the displacement loop (D-loop) and cytochrome $\mathrm{b}$ region of the mitochondrial deoxyribonucleic acid (mtDNA). A total of 28 samples (15 from South-South and 13 from SouthWest) were used for the genetic analysis. DNA was extracted from the tissue of all the samples using Quik-gDNA ${ }^{\mathrm{TM}}$ miniPrep kit. The D-loop containing the hypervariable region was sequenced for all samples from the two populations, while cytochrome b (Cyt b) region of mtDNA was only sequenced for samples from South-South population. Chromatograms of the sequences were viewed and edited using Bioedit software. Multiple sequence alignment was carried out using molecular evolutionary genetic analysis (MEGA) software before subsequent genetic analyses. Phylogenetic analysis grouped the samples into two clusters based on population. Also, when the two mitochondrial regions were pooled together, they clustered into two major groups based on mitochondrial regions. Analysis of molecular variance (AMOVA) revealed $37.32 \%$ variation within population and $62.68 \%$ variation among population with a significant fixation index of $0.627(\mathrm{p}<0.05)$. The genetic distance inferred between D-loop regions of South-South and South-West populations was 0.243 . Maternal lineage analysis revealed that the origin of tilapia fish
\end{abstract}


from both populations could be traced to Oreochromis spirilus and Oreochromis leucostictus based on mitochondrial D-loop region. The findings of this study revealed molecular divergence among the tilapia populations and may serve as pivot information for the genetic improvement of this important species.

\section{Keywords}

Phylogenetics, Molecular Divergence, Maternal Lineage, Tilapia Fish

\section{Introduction}

The Nile tilapia (Oreochromis niloticus) is the most commonly farmed tilapia species in Nigeria with good aquaculture qualities such as ability to withstand poor water quality and wide range of feed that support its cultivation. Reference [1] reported that tilapia has fast growth rate that can be further improved in a more favourable environment. According to [2], Nile tilapia has special features such as cycloid scales, grey/black body bars, pointed mouth part that ease it identification. As a maritime nation, integrating tilapia farming into agricultural schemes will be a necessary step towards addressing the problem of protein malnutrition, which is currently a challenge faced by many impoverished Nigerians. Comparing the nutritional values of tilapia to other animal protein sources, [3] documented protein content of $20.1 \mathrm{~g}, 18.6 \mathrm{~g}$ and $21.2 \mathrm{~g}$ and cholesterol content of $50 \mathrm{mg}, 68 \mathrm{mg}$ and $64 \mathrm{mg}$ per $100 \mathrm{~g}$ of tilapia, beef and chicken respectively. Although catfish is the most farmed fish in Nigeria, tilapia is a good candidate that could compete with catfish farming and consumption if given adequate research attention. It had been earlier reported that the total fat of $6 \mathrm{~g}$ and $18 \mathrm{~g} ; 59 \mathrm{~g}$ and $42 \mathrm{~g}$ protein content; $130 \mathrm{mg}$ and $145 \mathrm{mg}$ cholesterol per 80 ounce are available in tilapia and catfish, respectively [4]. With the growing rate of insecurity in the country, the number of internally displaced people is consequentially increased daily. These people are faced with malnutrition, especially protein malnutrition in their various camps across the country leading to high mortality rate. Although government has made effort to meet the nutrient requirement of these unfortunate Nigerians, this effort is not just sufficient and as such, sourcing protein from tilapia fish to meet this need may be advantageous considering that it is cheaper, readily accessible, with high protein content and other nutritionally essential elements needed for body growth. The challenge in achieving this objective is that Nigeria is far behind in fish production [5] with an estimated N125 billion spent annually on fish importation that has left the country as the highest importers of fish in developing countries [6]. Also, there is a serious concern over the possible genetic erosion of tilapia fish perceived from the continuous exploitation and indiscriminate fishing from the wild by local fishermen to meet market demand.

Overcoming the present doom demands intensified efforts and interest in fish research and production especially tilapia fish which has received very little or 
no research interest over the past years. This will pave new way for possible integration of tilapia fish farming into agricultural programmes. To achieve this, it is necessary to assess the different ecosystems where tilapia fish species are available as well as identifying reliable methods for their proper management, conservation and genetic improvement. Genetic variation and phylogenetic studies which assess the variation and relationships existing within and between populations have recently become an integral part in agricultural programmes as a tool for selection of breeding stock and characterization of species for possible conservation [7]. A good insight into the pattern of variation as well as the relationship in a population is a requisite for producing improved breeds. These relationships could be studied via morphological data from a population. Although morphometric method is the simplest and the most direct way used for fish identification and characterization [8] [9], it may not be very reliable for phylogeny considering that it is more subjected to environmental influences [10] [11] [12]. To fill this gap, different marker techniques have been developed and used for fish phylogenetics. The use of biochemical methods such as isozymes and protein banding patterns has been promising [13] [14]. Protein banding methods are often less informative and are used as preliminary phylogenetic investigative tool [15]. The advent of genetic markers such as RAPD, RFLP, and microsatellite in conjunction with statistical tools has revolutionized population studies geared towards exploring the phylogenetic relationships within and between populations. Importantly, DNA sequence data have proven to be the most direct and reliable method of assessing the pattern of variation and relationships among species.

Sequence data may be obtained from mtDNA or nuclear DNA. However, mtDNA found within the cytoplasm of a cell remains a good choice over nuclear DNA for phylogenetic studies due to the fast rate of mutation in the region [16] [17] and specificity as it is inherited only through maternal cell line [18]. These features of mtDNA are used by evolutionary biologists to establish relationships and to trace maternal lineage of species using array of sequence data. The displacement loop (D-loop) is the most variable region of mtDNA [19] and previous research reported that high variation in the region is useful in characterizing tilapia species [20] [21] [22]. Similarly, cytochrome b (Cytb) region of mtDNA has been used to establish the phylogenetic relationships within and between populations [17] [23] [24] [25] [26] [27]. In the present study, it was our aim to assess the phylogenetics of Oreochromis niloticus, a common species of tilapia fish in Nigeria using mitochondrial D-loop and Cytb.

\section{Materials and Methods}

\subsection{Location and Sample Collection}

A total of 28 samples of $O$. niloticus were collected from two populations for this study. The samples were identified in the Fishery Unit of the Institute of Oceanography, University of Calabar. Fifteen samples were obtained from Domita 


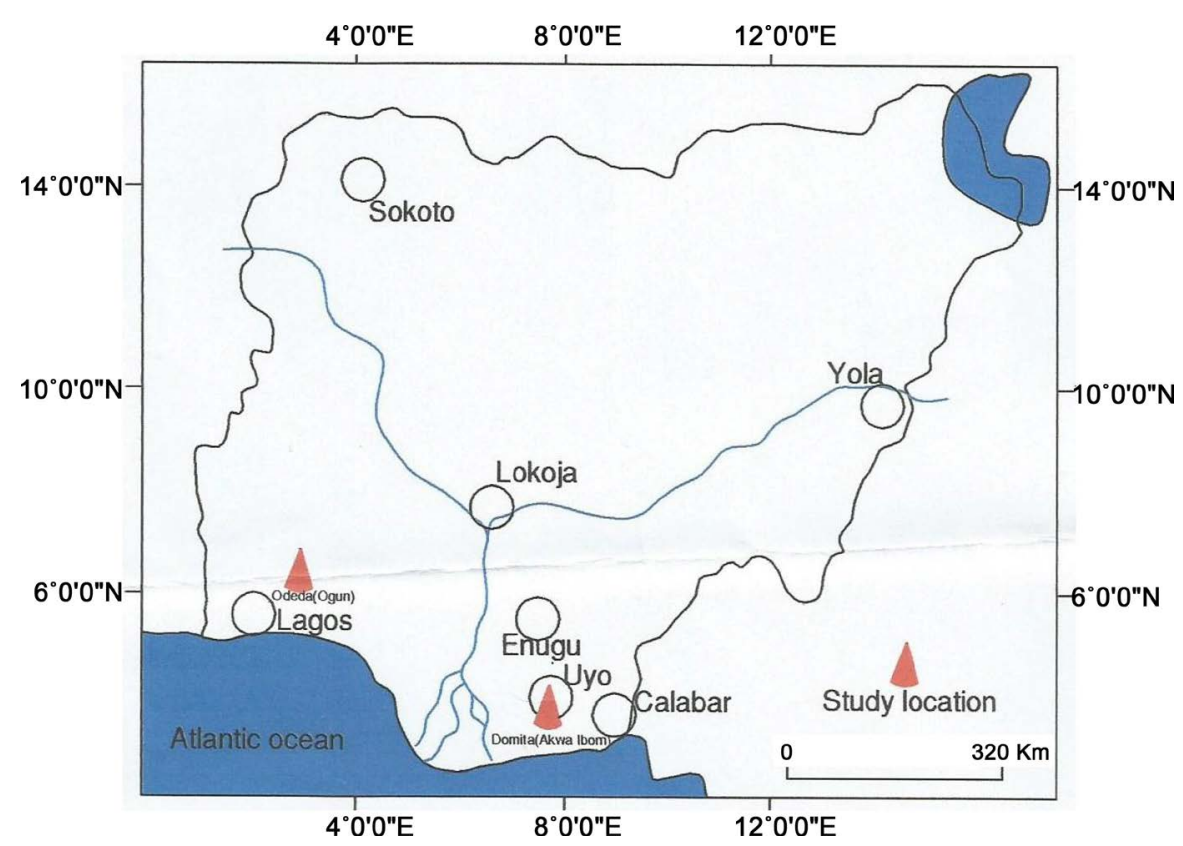

Figure 1. Map of Nigeria showing sampling locations.

Farm in Akwa Ibom State, a South-South region of Nigeria located at approximately $5^{\circ} 1^{\prime} 4^{\prime \prime N}, 7^{\circ} 59^{\prime} 52^{\prime \prime E}$. Thirteen samples were obtained from Odeda Farm in Ogun State, a South-West region of Nigeria located at $7^{\circ} 13^{\prime} 00^{\prime \prime} \mathrm{N}, 3^{\circ} 31^{\prime} 00^{\prime \prime} \mathrm{E}$ (Figure 1).

\subsection{DNA Isolation}

DNA was extracted from the tissue samples of all the fish using Quick-gDNA ${ }^{\mathrm{TM}}$ MiniPrep kit (Zymo Research, USA). Beta-mecaptoethanol was added to the lysis buffer to a final solution of $500 \mu \mathrm{l}$ per $100 \mathrm{ml}$ according to the manufacturer's instruction. Approximately $25 \mathrm{mg}$ of each fish tissue was homogenized in $500 \mu \mathrm{l}$ of genomic lysis buffer in Ependorff tube. The lysate was centrifuged at $10000 \times$ g under room temperature for five minutes using a Centurion Scientific microcentrifuge (Model: C2015, USA). The supernatant was carefully transferred to a Zymo-Spin ${ }^{\mathrm{TM}}$ column in a collection tube and centrifuged at $10,000 \times \mathrm{g}$ for one minute. Both the flow through and the collection tube were then discarded before transferring the Zymo-Spin ${ }^{\mathrm{TM}}$ column to a new collection tube. $200 \mu \mathrm{l}$ of DNA pre-wash buffer was added to the spin column and centrifuged at 10,000 $\times$ $\mathrm{g}$ for one minute. $500 \mu \mathrm{l}$ of g-DNA wash buffer was added to the spin column and further centrifuged at $10000 \times \mathrm{g}$ for one minute. The spin column was transferred to a clean microcentrifuge tube and $\geq 50 \mu \mathrm{l}$ of DNA elution buffer was added to the spin column. This was incubated for two to five minutes at room temperature and afterward centrifuged at top speed $(14,000 \times \mathrm{g})$ for 30 seconds to elute the DNA. The eluted DNA was stored at $-20^{\circ} \mathrm{C}$ for further analysis.

\subsection{PCR Amplification}

PCR amplification was carried out using the primers Fish-comum-D-loop For- 
ward (5'-GGATTYTAACCCYTRCCCC-3') and Czilli Reverse (3'-AGTAAAG TCAGGACCAAGCC-5') for D-loop region as previously used by [22]. Czilli Forward (5'-GGATTTTAACCCTTACCCC-3') and Czilli Reverse (3'AGTAAAGTCAGGACCAAGCC-5') were designed and used for cytochrome $b$ region of the mtDNA. PCR for each mtDNA region was carried out using $25 \mu \mathrm{l}$ reaction volume containing $1 \mu \mathrm{l}$ genomic DNA, $2 \mathrm{mM} \mathrm{MgCl}_{2}, 200 \mu \mathrm{M}$ of dNTP, $2.5 \mu \mathrm{l}$ of $10 \times$ PCR buffer, $1 \mu \mathrm{M}$ of each primer and two units of STABVIDA proprietary Taq polymerase. This was performed using the GeneAmp PCR system (9700 thermal cycler, USA) with the cycling condition of initial denaturation step at $95^{\circ} \mathrm{C}$ for five minutes, followed by 25 cycles of denaturation at $94^{\circ} \mathrm{C}$ for 40 seconds, annealing at $54^{\circ} \mathrm{C}$ for 45 seconds, extension at $72^{\circ} \mathrm{C}$ for one minute and final extension at $72^{\circ} \mathrm{C}$ for seven minutes. PCR products were purified using exofast protocol according to the manufacturer.

\subsection{Sequencing of D-Loop and Cytochrome b Regions of mtDNA}

D-loop and cytochrome $b$ region of the mtDNA were sequenced for all tissueDNA extracts using the primers (5'-GGATTYTAACCCYTRCCCC-3') and Czilli Reverse (3'-AGTAAAGTCAGGACCAAGCC-5') for D-loop region and Czilli Forward (5'-GGATTTTAACCCTTACCCC-3') and Czilli Reverse (3'AGTAAAGTCAGGACCAAGCC-5') for cytochrome b region. Sequencing reaction was performed with $\mathrm{AB} 13730 \times \mathrm{L}$ sequencer using $20 \mu \mathrm{l}$ reaction comprising approximately $20 \mathrm{ng}$ of purified PCR product as template DNA, $8 \mu \mathrm{l}$ of Big Dye Terminator Reaction Mix (dNTPs, ddNTPs, buffer, enzyme and $\mathrm{MgCl}_{2}$ ), 8 $\mu \mathrm{l}$ of deionized water, $2 \mu \mathrm{l}$ of primer programmed as 25 cycles at $96^{\circ} \mathrm{C}$ for 10 seconds, $50^{\circ} \mathrm{C}$ for five seconds and $60^{\circ} \mathrm{C}$ for four minutes [28]. The length of the sequenced fragments ranged from 950 to 1366 bp for D-loop and 1241 to 1401 bp for cytochrome b.

\subsection{Statistical Analysis}

Bioedit software version 7.2.5 [29] was used to view and edit the sequences. MEGA 6.06 was used for multiple sequence alignment of all the samples [30] excluding all the gaps. Analysis of molecular variance (AMOVA) was determined using Arlequin 3.5.1.3 software [31]. Arlequin was also used to compute the fixation index among the populations which was computed as the average of the variance among the populations by the total variance observed in the population. The genetic distance and phylogenetic analysis of samples from the populations was performed using MEGA 6.06 [30]. To classify the species into maternal lineage, D-loop sequences of other tilapia species were retrieved from GenBank with the following accession numbers: KX757836.1, KX767829.1, EU163710.1, FJ664225.1, EU308500.2, EU430997.2, AF296483.1, FJ664233.1, AF296455.1, AF296460.1 and FJ664215.1 while cyt reference with the following accession numbers: AB018989.1, X81565.1, AF375617.1, HM049957.1, EF059808.1, KX347644.1, JQ755415.1, EF679275.1, KX347652.1, EF679291.1, KX347643.1 
and AF370632.1 were used. These were all aligned with the query sequences obtained from tilapia in the studied populations to construct a maximum likelihood tree using MEGA 6.06 with 1000 bootstrap replications [30].

\section{Results}

\subsection{Phylogenetic Relationship Analysis}

The Neighbor-Joining phylogenetic relationship of tilapia fish from the two populations based on mitochondrial D-loop is presented in Figure 2. The numbers at the node represent the percentage bootstrap values for branches with

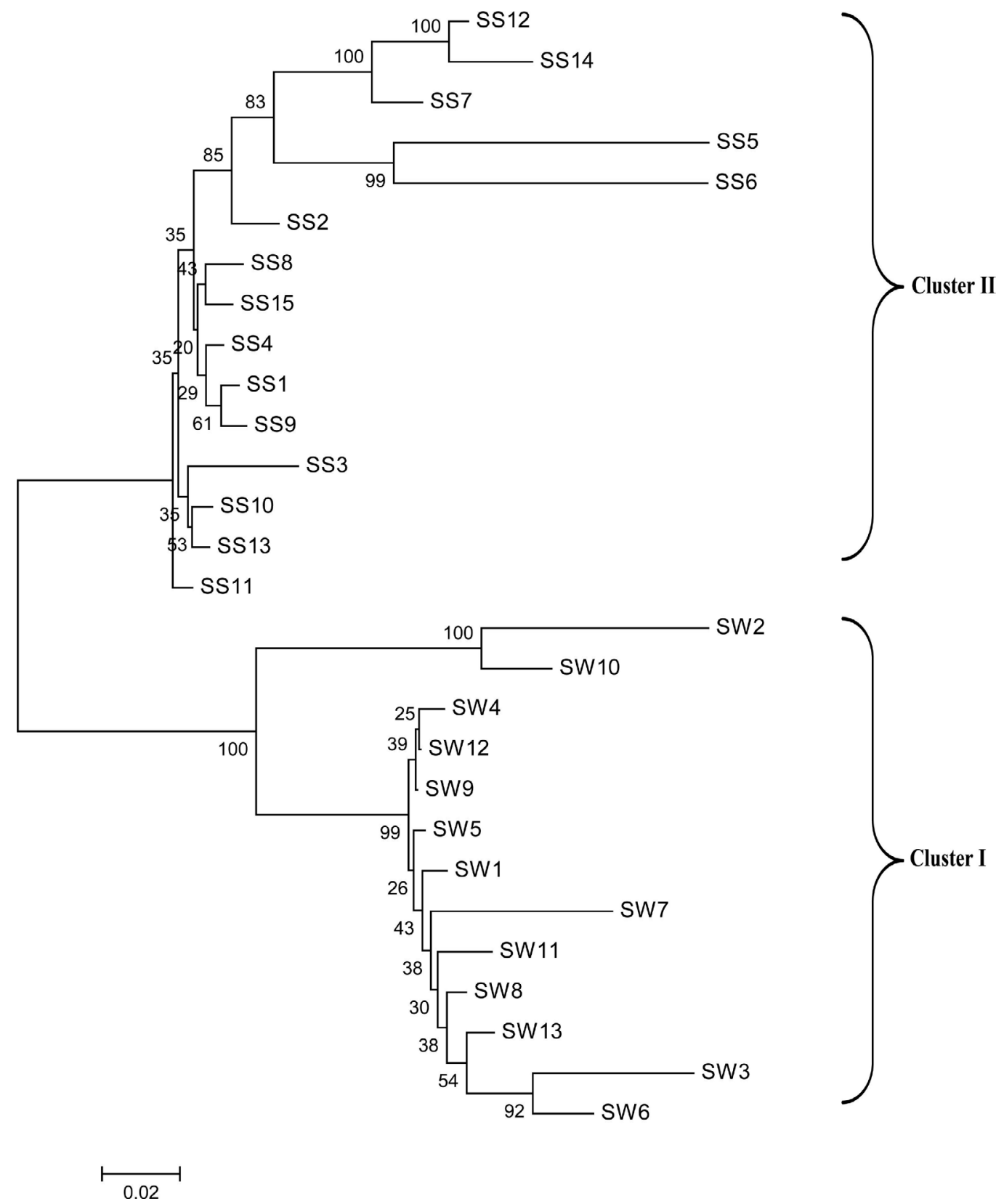

Figure 2. Neighbor-Joining phylogenetic tree showing the relationship between tilapia fish from two populations based on mtDNA D-loop region (SS = South-South; SW = South-West). 


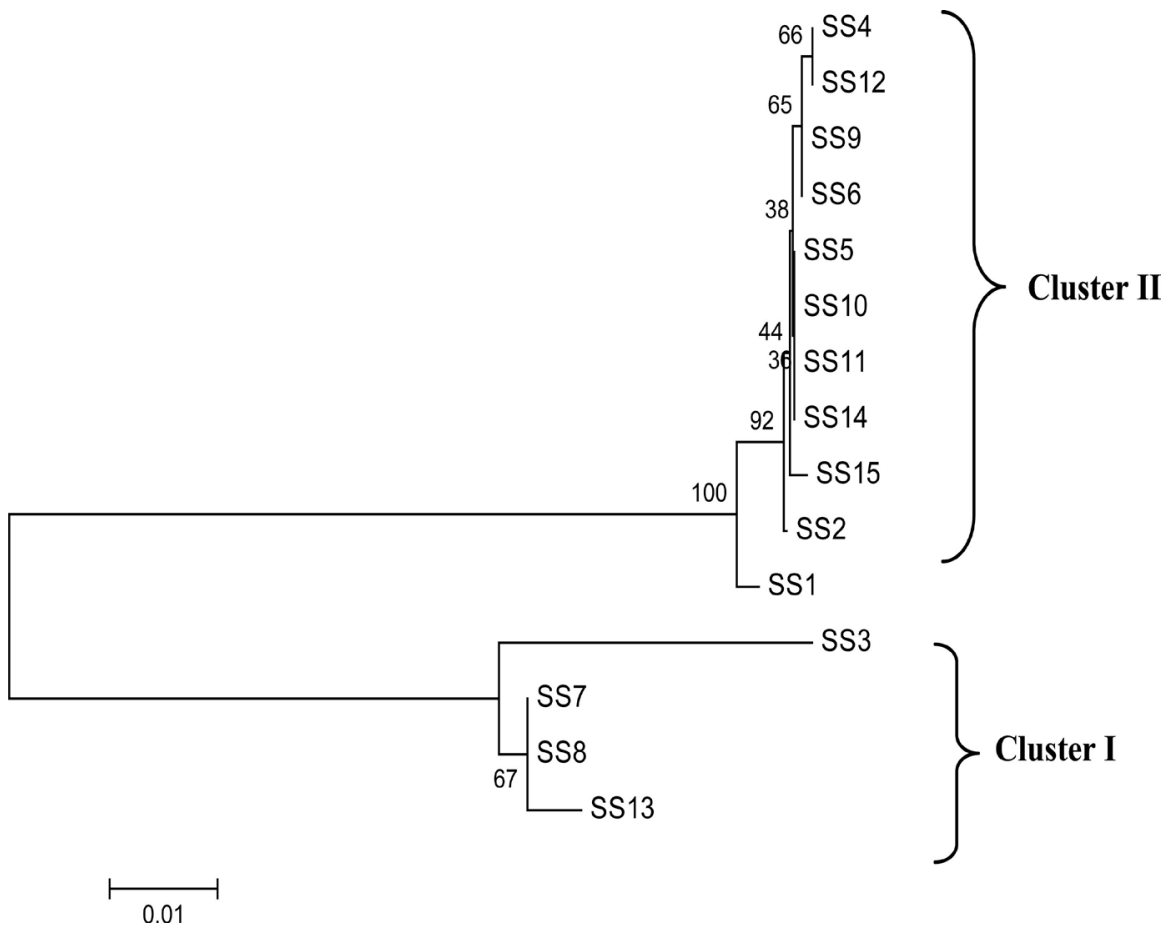

Figure 3. Neighbor-Joining phylogenetic tree showing the relationship between tilapia fish from South-South population based on mtDNA Cyt b (SS = South-South).

1000 bootstrap replications. Two major clusters were revealed, which were based on populations. Cluster I consisted of all the samples from South-West D-loop with assigned sequence accession number: MF385002 sub-clustered into two groups. Similarly, cluster II consisted of all the samples from South-South D-loop with assigned sequence accession number: MF385001. SS11 was separated into a different lineage from other samples within the South-South population. For mtDNA Cyt b with sequence accession number: MF384326, two major clusters were also revealed where SS3, SS7, SS8 and SS13 shared the same lineage (Figure 3). The comparative clustering of D-loop and cyt b separated the samples into two major clusters based on mitochondrial DNA regions. Samples from South-South and South-West D-loop were grouped together under the same major cluster while samples sequenced for cyt $\mathrm{b}$ had a different lineage as shown in Figure 4.

\subsection{Analysis of Molecular Variance (AMOVA)}

From Table 1, AMOVA revealed that molecular genetic variation among populations was higher $(62.68 \%)$ than within population variation $(37.32 \%)$ inferred from the D-loop of the two populations. Additionally, fixation index was 0.627 , which made the variation significant $(\mathrm{p}<0.05)$.

\subsection{Genetic Distance}

The genetic distance between tilapia fish from South-South and South-West population was 0.243 . From Table 2, the highest genetic distance within mito- 


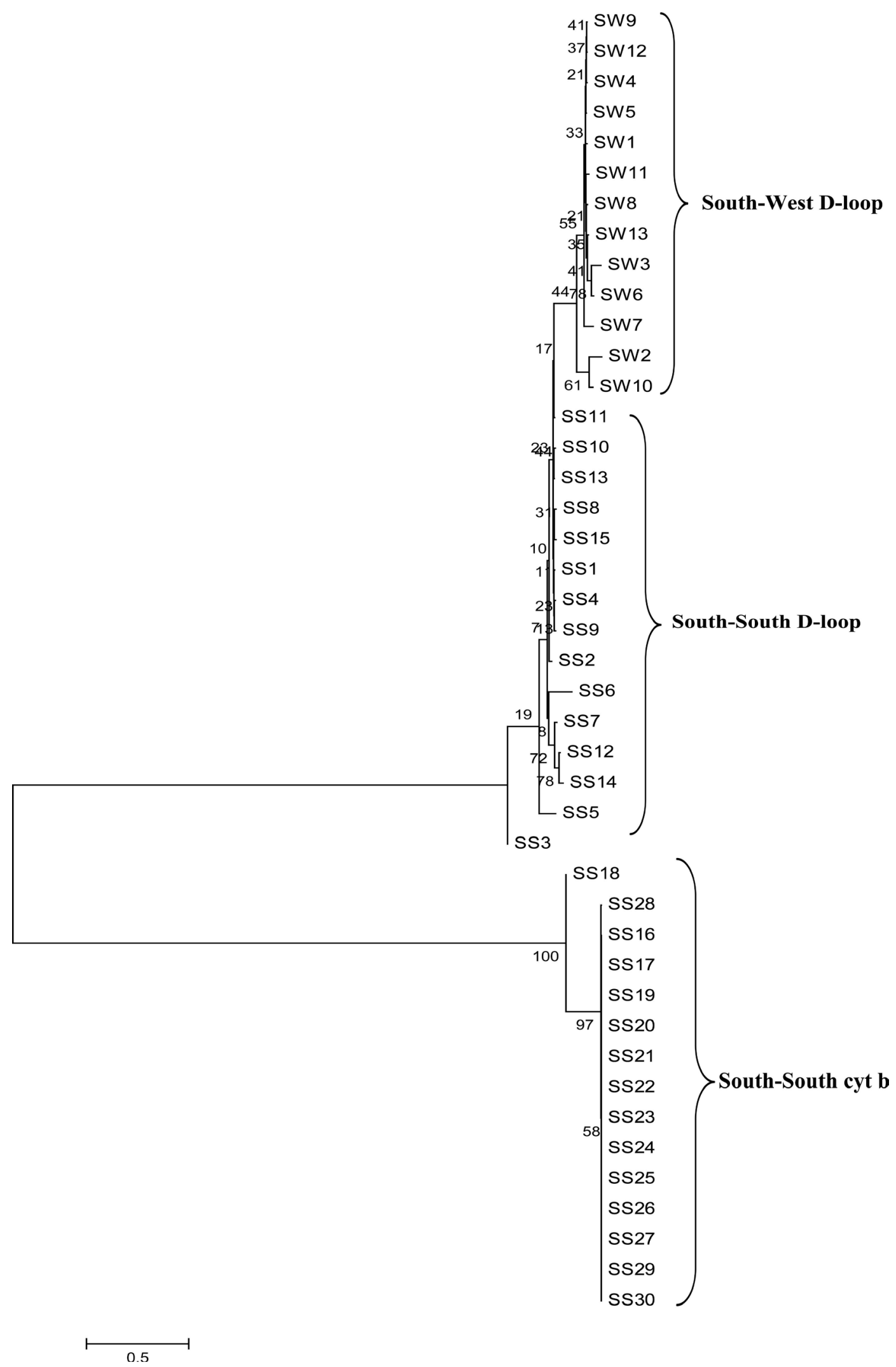

Figure 4. Neighbor-Joining phylogenetic tree showing the relationship between tilapia fish based on two mtDNA regions [SS1-15 = South-South D-loop; SS16-SS30 = South-South cyt b; SW1-13 = South-West D-loop]. 
Table 1. AMOVA showing genetic variation within and between tilapia in South-South and South-West Nigeria.

\begin{tabular}{cccccc}
\hline SOV & Df & SS & Variance components & \%Variance & $F_{S T}$ \\
\hline Among populations & 1 & 613.704 & 42.255 & 62.68 & $0.627(\mathrm{p}<0.05)$ \\
Within populations & 26 & 654.046 & 25.156 & 37.32 & \\
Total & 27 & 1267.750 & 67.410 & & \\
\hline
\end{tabular}

SOV (source of variation); df (degree of freedom); SS (sum of squares); $\mathrm{F}_{\mathrm{ST}}$ (fixation index).

Table 2. Pairwise genetic distance of tilapia fish from South-South Nigeria based on mitochondrial D-loop region.

\begin{tabular}{|c|c|c|c|c|c|c|c|c|c|c|c|c|c|c|c|}
\hline & SS1 & SS2 & SS3 & SS4 & SS5 & SS6 & SS7 & SS8 & SS9 & SS10 & SS11 & SS12 & SS13 & SS14 & SS15 \\
\hline SS1 & 0 & & & & & & & & & & & & & & \\
\hline SS2 & 0.036 & 0 & & & & & & & & & & & & & \\
\hline SS3 & 0.047 & 0.053 & 0 & & & & & & & & & & & & \\
\hline SS4 & 0.014 & 0.025 & 0.044 & 0 & & & & & & & & & & & \\
\hline SS5 & 0.152 & 0.147 & 0.155 & 0.145 & 0 & & & & & & & & & & \\
\hline SS6 & 0.154 & 0.139 & 0.160 & 0.147 & 0.160 & 0 & & & & & & & & & \\
\hline SS7 & 0.075 & 0.057 & 0.076 & 0.066 & 0.160 & 0.154 & 0 & & & & & & & & \\
\hline SS8 & 0.019 & 0.033 & 0.050 & 0.019 & 0.145 & 0.147 & 0.066 & 0 & & & & & & & \\
\hline SS9 & 0.011 & 0.030 & 0.050 & 0.014 & 0.154 & 0.152 & 0.069 & 0.027 & 0 & & & & & & \\
\hline SS10 & 0.019 & 0.039 & 0.033 & 0.019 & 0.152 & 0.150 & 0.072 & 0.022 & 0.022 & 0 & & & & & \\
\hline SS11 & 0.014 & 0.033 & 0.036 & 0.016 & 0.149 & 0.147 & 0.075 & 0.025 & 0.019 & 0.016 & 0 & & & & \\
\hline SS12 & 0.090 & 0.060 & 0.091 & 0.078 & 0.172 & 0.154 & 0.039 & 0.081 & 0.081 & 0.090 & 0.090 & 0 & & & \\
\hline SS13 & 0.023 & 0.037 & 0.034 & 0.020 & 0.149 & 0.144 & 0.068 & 0.023 & 0.023 & 0.009 & 0.015 & 0.089 & 0 & & \\
\hline SS14 & 0.110 & 0.080 & 0.099 & 0.098 & 0.174 & 0.162 & 0.052 & 0.101 & 0.101 & 0.110 & 0.107 & 0.026 & 0.102 & 0 & \\
\hline SS15 & 0.022 & 0.030 & 0.047 & 0.014 & 0.150 & 0.144 & 0.060 & 0.016 & 0.019 & 0.022 & 0.022 & 0.078 & 0.018 & 0.092 & 0 \\
\hline
\end{tabular}

SS (South-South).

chondrial D-loop of tilapia from South-South population was between SS5 and SS14 (0.174), while the lowest distance was between SS10 and SS13 (0.009). The highest genetic distance within South-West population was 0.133 recorded between SW2 and SW6 and between SW3 and SW10, while the lowest distance was between SW9 and SW12 (0.002), Table 3. Similarly, Table 4 showed that the highest genetic distance within mitochondrial Cyt b of South-South population was 0.149 (SS3 and SS12) while the lowest genetic distance was 0.000 (SS7 and SS8, SS6 and SS9, SS5 and SS10, SS5 and SS11, SS10 and SS11, SS4 and SS12, SS5 and SS14, SS10 and SS14, SS11 and SS14).

\subsection{Maternal Lineage}

Unweighted Pair Group Method with Arithmetic Means (UPGMA) tree constructed using the query sequence of tilapia fish from South-South and SouthWest populations with 10 reference sequences obtained from GenBank (KX757836.1, KX767829.1, EU163710.1, FJ664225.1, EU308500.2, EU430997.2, AF296483.1, 
Table 3. Pairwise genetic distance of tilapia fish from South-West Nigeria based on mitochondrial D-loop region.

\begin{tabular}{|c|c|c|c|c|c|c|c|c|c|c|c|c|c|}
\hline & SW1 & SW2 & SW3 & SW4 & SW5 & SW6 & SW7 & SW8 & SW9 & SW10 & SW11 & SW12 & SW13 \\
\hline SW1 & 0 & & & & & & & & & & & & \\
\hline SW2 & 0.116 & 0 & & & & & & & & & & & \\
\hline SW3 & 0.052 & 0.123 & 0 & & & & & & & & & & \\
\hline SW4 & 0.010 & 0.117 & 0.055 & 0 & & & & & & & & & \\
\hline SW5 & 0.007 & 0.117 & 0.053 & 0.006 & 0 & & & & & & & & \\
\hline SW6 & 0.033 & 0.133 & 0.039 & 0.034 & 0.033 & 0 & & & & & & & \\
\hline SW7 & 0.039 & 0.097 & 0.060 & 0.042 & 0.040 & 0.065 & 0 & & & & & & \\
\hline SW8 & 0.009 & 0.119 & 0.045 & 0.012 & 0.009 & 0.025 & 0.042 & 0 & & & & & \\
\hline SW9 & 0.009 & 0.116 & 0.056 & 0.005 & 0.004 & 0.037 & 0.043 & 0.013 & 0 & & & & \\
\hline SW10 & 0.088 & 0.052 & 0.133 & 0.081 & 0.083 & 0.111 & 0.123 & 0.093 & 0.078 & 0 & & & \\
\hline SW11 & 0.016 & 0.123 & 0.058 & 0.015 & 0.012 & 0.038 & 0.043 & 0.014 & 0.016 & 0.092 & 0 & & \\
\hline SW12 & 0.009 & 0.118 & 0.056 & 0.005 & 0.005 & 0.037 & 0.045 & 0.011 & 0.002 & 0.080 & 0.016 & 0 & \\
\hline SW13 & 0.014 & 0.120 & 0.045 & 0.011 & 0.014 & 0.026 & 0.042 & 0.014 & 0.016 & 0.090 & 0.017 & 0.016 & 0 \\
\hline
\end{tabular}

SW (South-West).

Table 4. Pairwise genetic distance of tilapia fish from South-South Nigeria based on mitochondrial Cyt b region.

\begin{tabular}{|c|c|c|c|c|c|c|c|c|c|c|c|c|c|c|c|}
\hline & SS1 & SS2 & SS3 & SS4 & SS5 & SS6 & SS7 & SS8 & SS9 & SS10 & SS11 & SS12 & SS13 & SS14 & SS15 \\
\hline SS1 & 0 & & & & & & & & & & & & & & \\
\hline SS2 & 0.007 & 0 & & & & & & & & & & & & & \\
\hline SS3 & 0.144 & 0.146 & 0 & & & & & & & & & & & & \\
\hline SS4 & 0.008 & 0.003 & 0.149 & 0 & & & & & & & & & & & \\
\hline SS5 & 0.008 & 0.001 & 0.148 & 0.002 & 0 & & & & & & & & & & \\
\hline SS6 & 0.007 & 0.002 & 0.148 & 0.001 & 0.001 & 0 & & & & & & & & & \\
\hline SS7 & 0.118 & 0.119 & 0.032 & 0.123 & 0.120 & 0.122 & 0 & & & & & & & & \\
\hline SS8 & 0.118 & 0.119 & 0.032 & 0.123 & 0.120 & 0.122 & 0.000 & 0 & & & & & & & \\
\hline SS9 & 0.007 & 0.002 & 0.148 & 0.001 & 0.001 & 0.000 & 0.122 & 0.122 & 0 & & & & & & \\
\hline SS10 & 0.008 & 0.001 & 0.148 & 0.002 & 0.000 & 0.001 & 0.120 & 0.120 & 0.001 & 0 & & & & & \\
\hline SS11 & 0.008 & 0.001 & 0.148 & 0.002 & 0.000 & 0.001 & 0.120 & 0.120 & 0.001 & 0.000 & 0 & & & & \\
\hline SS12 & 0.008 & 0.003 & 0.149 & 0.000 & 0.002 & 0.001 & 0.123 & 0.123 & 0.001 & 0.002 & 0.002 & 0 & & & \\
\hline SS13 & 0.122 & 0.126 & 0.035 & 0.127 & 0.127 & 0.126 & 0.005 & 0.005 & 0.126 & 0.127 & 0.127 & 0.127 & 0 & & \\
\hline SS14 & 0.008 & 0.001 & 0.148 & 0.002 & 0.000 & 0.001 & 0.120 & 0.120 & 0.001 & 0.000 & 0.000 & 0.002 & 0.127 & 0 & \\
\hline SS15 & 0.010 & 0.003 & 0.145 & 0.004 & 0.002 & 0.003 & 0.120 & 0.120 & 0.003 & 0.002 & 0.002 & 0.004 & 0.125 & 0.002 & 0 \\
\hline
\end{tabular}

SS (South-South).

FJ664233.1, AF296455.1, AF296460.1 and FJ664215.1) is presented in Figure 5 and Figure 6. From the lineage analysis, tilapia fish from South-South population used in this study shared the same lineage with Oreochromis aureus, while tilapia from South-West population shared the same lineage with Tilapia zillii 
from GenBank. Similar result was obtained when mtDNA cyt b reference sequences (AB018989.1, X81565.1, AF375617.1, HM049957.1, EF059808.1, KX347644.1, JQ755415.1, EF679275.1, KX347652.1, EF679291.1, KX347643.1 and AF370632.1) were compared with South-South population (Figure 7).

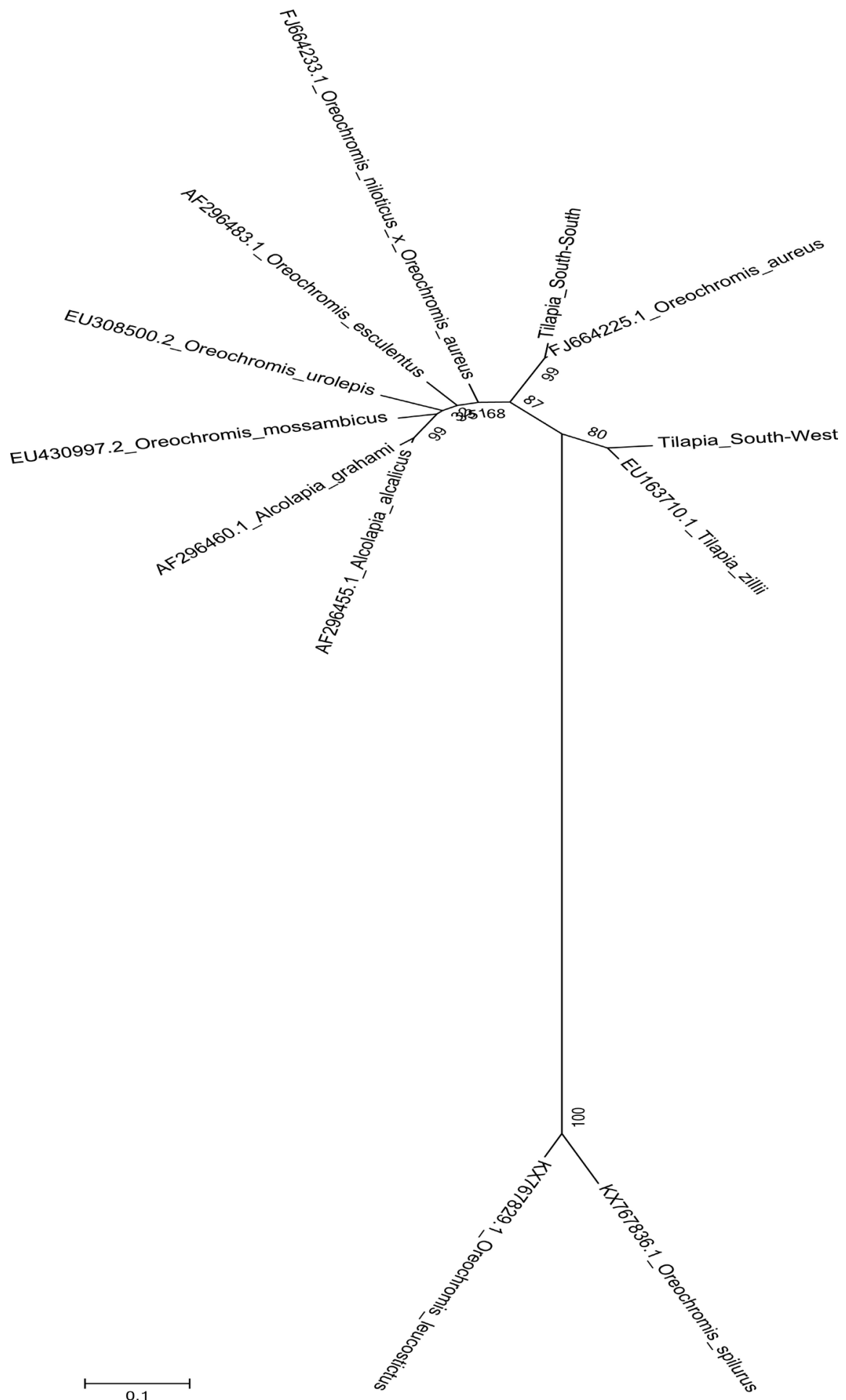

Figure 5. Maximum likelihood phylogenetic tree showing maternal lineage of tilapia fish from South-South and South-West Nigeria based on mitochondrial D-loop. 


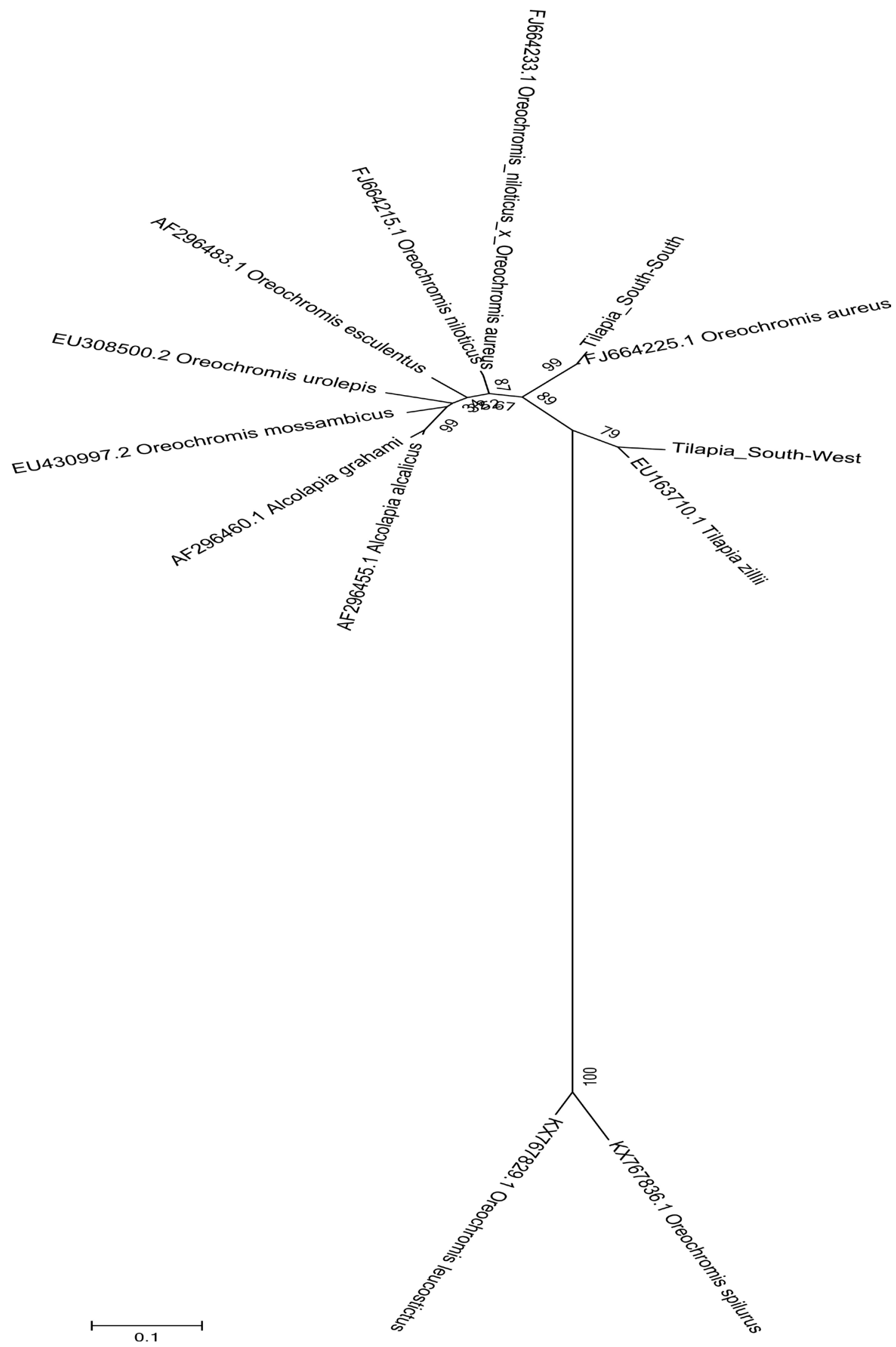

Figure 6. Maximum likelihood phylogenetic tree showing maternal lineage of tilapia fish from South-South and South-West Nigeria based on mitochondrial D-loop. 


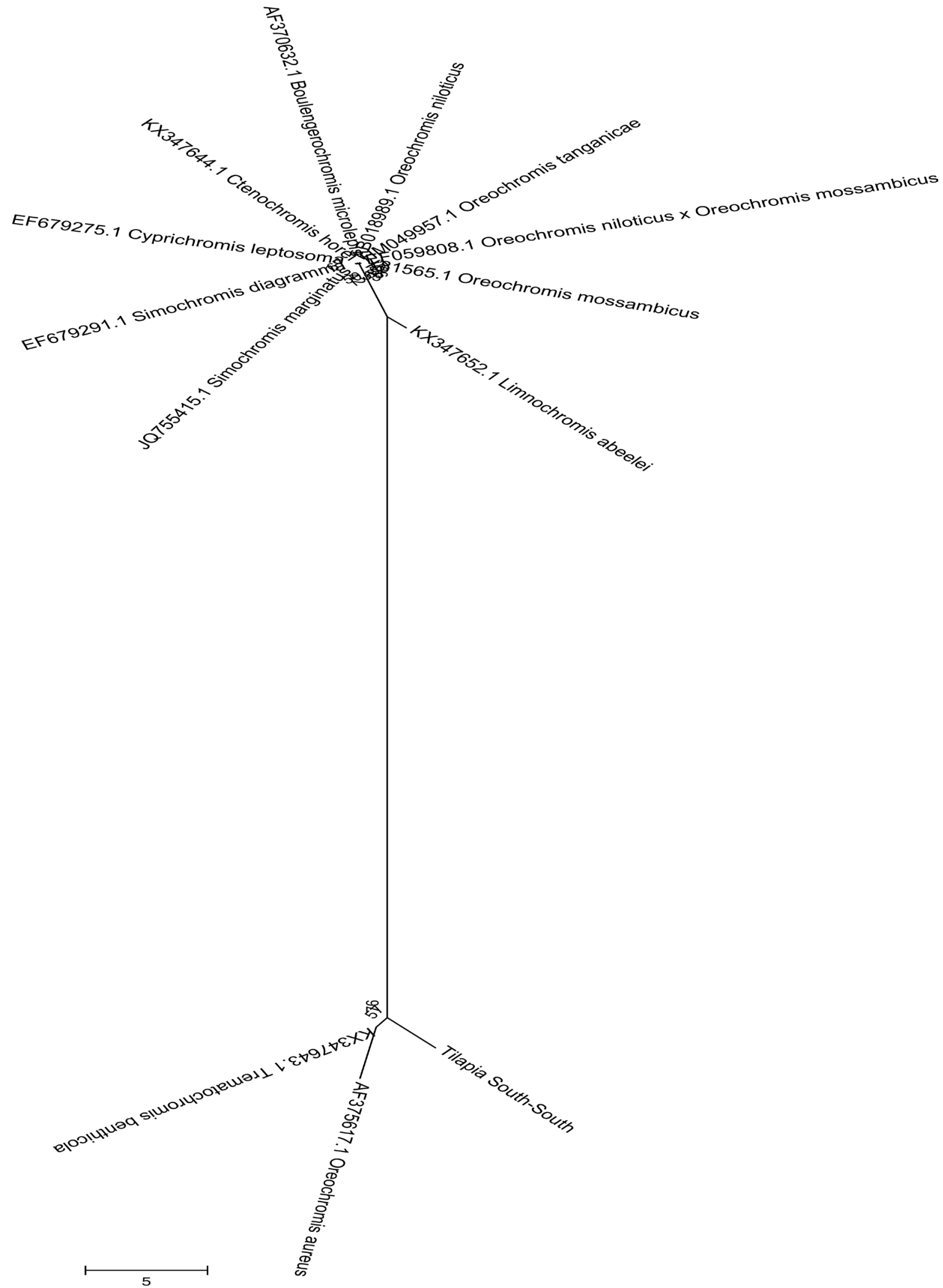

Figure 7. Maximum likelihood phylogenetic tree showing maternal lineage of tilapia fish from South-South Nigeria based on mitochondrial Cyt b. 


\section{Discussion}

Understanding the genetic architecture of species in a population is very critical in developing conservation and management strategies for endangered species [32]. Tilapia fish is highly migratory species with high rate of introgression, which may alter their genetic originality. Thus, for management and improvement of this important species, it becomes imperative to assess their genetic blue-print and relationships.

The importance of understanding the phylogenetic relationship existing within and between species in a population cannot be overemphasized as it has become a handy method used in tracing the origin and evolution of species, prediction of physiological, biochemical and structural features of sequences obtained from organism [33]. Phylogenetic tree can be constructed using different features and characters of species such as morphology, RAPD information or sequence data of the DNA. Important to note is the reliability of sequence data over other methods in establishing the relationship between closely related species [34]. In this study, the phylogenetic tree constructed from the sequence data (D-loon and cyt b) of samples from the two populations clearly separated the samples into two major clusters based on population. All samples from SouthSouth population were grouped under the same major cluster while South-West samples clustered under a common group. This could suggest that the two populations are genetically distinct although they may share a common ancestor. The findings here corroborate the earlier report by [22] that populations of tilapia species in Nigeria showed no evidence of sub-structuring in their phylogeny but may be traced to a single ancestral lineage. Similarly, phylogenetic analysis by [35] and [36] also revealed population-based phylogenetic clustering of fish. Comparing the two mitochondrial DNA regions showed that the samples are genetically distinct as they were specifically grouped based on the two mitochondrial regions used for the study. Although D-loop was sequenced for two different populations, the samples from these populations shared the same major cluster. This might suggest that sequence evolution of mtDNA D-loop region is not environmentally influenced but the differences could be traced to other factors inherent in the sequence. Also, the fact that there was no intertwining of D-loop and cyt b samples on the phylogenetic tree could be an indication of the dissimilarity of these regions in predicting evolutionary trends [19]. Phylogeny of the two populations corroborates the findings of the genetic distance based on D-loop region. In South-South population, samples with the highest genetic distance (SS5 and SS14) were found in separate sub-clusters, while the lowest genetic distance (SS10 and SS13) were sub-clustered together with a bootstrap value of 83. In South-West population, the highest genetic distance (SW2 and SW6) were in different sub-clusters, while the lowest distance observed between SW9 and SW12 were in the same sub-clusters.

Analysis of molecular variance (AMOVA) using D-loop suggested low genetic variance within the population (37.32\%) and high genetic variation among the 
population (62.68\%), which could be an indication of a strong population differentiation between the two populations. This agreed with the findings of [32], where low within population and high between population variations was reported among Channa fish. The AMOVA result on among population molecular variation (62.68\%) is also a good explanation to the different clustering of tilapia populations observed, the mitochondrial DNA region notwithstanding. The molecular variation among populations may not have been unconnected with natural selection or genetic drifts, which are hinged on evolution via random mutation. Sewall Wright effect (allelic drift) changes the frequency of an existing allele in a population as a result of random sampling of organisms. This may however, cause gene variants to disappear completely and thereby reduce genetic variation [37]. This might implicitly account for the differences observed between tilapia fish population of South-South/South-West mtDNA D-loop region and mtDNA D-loop and cyt b of South-South. Fixation index is used to differentiate populations and has been employed by molecular biologists to examine the genetic variations in population and the contribution of such variations in differentiating populations [38]. The fixation index $\left(F_{S T}\right)$ value was significant between the two populations used in this study (0.627) suggesting further that the two populations are genetically different. The result may be an indication that the two populations may have evolved in isolation after diverging from a common ancestor. This could be further explained by the result of the maternal lineage analysis using mitochondrial D-loop region where the origin of tilapia fish from the two populations was traced to Oreochromis spirilus and Oreochromis leucostictus. However, during evolution, tilapia from South-South population separated into a different lineage with Oreochromis aureus while tilapia from South-West population shared lineage with Tilapia zillii. Furthermore, our result on maternal lineage suggests that the mtDNA D-loop of tilapia fish sampled from South-South shared $99 \%$ similarity with Oreochromis aureus. It is important to mention that the most common tilapia fish species in Africa are Oreochromis niloticus and Oreochromis aureus. The difference between the mtDNA D-loop region of tilapia fish sampled from South-South and South-West may be traced to the fact that the tilapia fish species from South-South could be Oreochromis aureus rather than Oreochromis niloticus. To further confirm this claim, sequence of O.niloticus from database was also used to construct the maternal lineage. The $O$. niloticus from database was rather clustered with a hybrid between $O$. niloticus $\times$ $O$. aureus, while our query sequence from South-South D-loop was still at $99 \%$ similarity with $O$. aureus. Cyt b though sequenced only from one population also linked the South-South samples to $O$. aureus. The findings here are very critical to both fish farmers and breeders who in the quest of setting up fish farms may purchase stock without adequate knowledge of their genetic blue print/species involved. This lack of understanding may even be the major contributing factor to the poor performance of tilapia fish as documented in literature because the specific feed/environment required to attain the maxi- 
mum performance of specific species of tilapia fish may not have been met. It therefore suggests that for better improvement of tilapia fish, there should be collaboration between geneticists, breeders and fish farmers.

The genetic distance between South-South and South-West populations based on D-loop was 0.243 , which was higher than within population genetic distance. Genetic distance measures the genetic differences between species/populations. Populations with similar alleles are expected to have low genetic distance as an indication of their genetic relatedness [39]. Therefore, genetic distance between the populations may be further indication of the molecular divergence between tilapia from South-South and South-West Nigeria. The result on the genetic distance further support the speculation that tilapia fish sampled from South-South and South-West may not be the same species as the genetic distance is wide. Going by the report of [39], it does suggest that the two populations might not be genetically related especially using mtDNA D-loop reference. The genetic unrelatedness may also be from the fact that due to random mutation, alleles that were similar from the ancestral root had changed frequency [40]. This divergence is important for the survivability of tilapia fish in the advent of environmental hazard. Comparing the within group genetic distance of D-loop and Cyt b of South-South population, the highest distance from D-loop was observed between SS5 and SS14 (0.174), while SS3 and SS12 (0.149) was highest based on Cyt b. Although from the same population, D-loop and Cyt b seem to predict the within group genetic distance differently which could be an indication that the two regions of mtDNA may not estimate genetic relatedness in a similar pattern. As it is reported that the mutation rate of the different regions of mtDNA are different [19], the findings of the present study may not be unexpected.

\section{Conclusion}

The findings of this study revealed the existence of molecular divergence between tilapia fish from the two geographical regions of Nigeria. Also, the two mtDNA regions used in this study showed dissimilarity in estimating genetic relatedness.

\section{Acknowledgements}

The authors wish to thank the Animal Genetics and Genomics unit, Department of Genetics and Biotechnology, University of Calabar, Nigeria for the support granted to facilitate this research.

\section{Conflict of Interest}

We declare that there is no conflict of interest in the manuscript from any author.

\section{References}

[1] Food and Agriculture Organization (2012) Cultured Aquatic Species Information 
Programme on Oreochromis niloticus. FAO Fisheries and Aquaculture Department, Rome.

[2] Picker, M.D. and Griffiths, C.L. (2011) Alien and Invasive Animals: A South African Perspective. Randomhouse/Struik, Cape Town.

[3] Agricultural Research Service (ARS), United States Department of Agriculture (USDA) (2009) Nutrient Data Release 22. http://www.ars.usda.gov/ba/bhnrc/ndl

[4] Sparkpeople (2013). Food vs. Food. http://www.sparkpeople.com/

[5] Oyakhilomen, O. and Zibah, R.G. (2013) Fishery Production and Economic Growth: Pathway for Sustainable Development. Journal of Sustainable Development, $15,2$.

[6] Agbo, D.I. (2015) Bridging the Fish Demand, Supply Gap in Nigeria. Daily Trust Newspaper, 14 May.

[7] De-Silva, M.P.K.S.K. (2015) Genetic Diversity of Genetically Improved Farmed Tilapia (GIFT) Broodstocks in Sri Lanka. International Journal of Scientific Research and Innovative Technology, 2, 66-76.

[8] Hockaday, S., Beddow, T.A., Stone, M., Hancock, P. and Ross, L.G. (2000) Using Truss Networks to Estimate the Biomass of Oreochromis niloticus and to Investigate Shape Characters. Journal of Fish Biology, 57, 981-1000.

[9] Samaradivakara, S.P., Hirimuthugoda, N.Y., Gunawardana, R.H.A.N.M., Illeperuma, R.J., Fernandopulle, N.D., De-Silva, A.D. and Alexander, P.A.B.D. (2012) Morphological Variation of Four Tilapia Populations in Selected Reservoirs in Sri Lanka. Tropical Agricultural Research, 23, 105-116.

[10] Thompson, J.D. (1991) Phenotypic Plasticity as a Component of Evolutionary Change. Trends in Ecology and Evolution, 6, 246-249.

[11] Wimberger, P.H. (1992) Plasticity of Fish Body Shape, the Effects of Diet, Development, Family and Age in Two Species of Geophagus (Pisces: Cichlidae). Biology Journal of Linnean Society, 45, 197-218.

[12] Ikpeme, E.V., Ekerette, E.E., Udensi, O.U. and Ozoje, M.O. (2017) Assessment of Morphological Variation in Wild and Cultured Populations of Tilapia Fish (Oreochromis niloticus). Journal of Advances in Biology \& Biotechnology, 13, 1-10.

[13] Na-Nakorn, U. (2001) Genetic Differentiation of Fishes in the Genera, Clarias and Prophagorus in Thailand, Using Protein Electrophoresis and RAPD-PCR. In: Baimai, V. and Kumhom, R., Eds., BRT Research Reports, Biodiversity Research Training Program, Jirawat Express, Bangkok.

[14] Jesslin, G., Sabaridasan, A., Edwinthahgam, P., Palanikani, R. and Soranam, R. (2013) Electrophoretic Studies on the Muscle Proteins of Three Species of Genus Puntius (Osteichthyes-Cyprinidae). International Journal of Research in Fisheries and Aquaculture, 2, 16-20.

[15] Adeleke, M.A., Peters, S.O., Ozoje, M.O., Ikeobi, C.O.N., Adebambo, A.O., Olowofeso, O., Bamgbose, A.M. and Adebambo, O.A. (2013) A Preliminary Screening of Genetic Lineage of Nigerian Local Chickens Based on Blood Protein Polymorphisms. Animal Genetic Resources, 48, 23-28.

[16] Wilson, A.C., Cann, R.L., Carr, S.M., George, M., Gyllensten, U.B., Helm-Bychowski, K.M., Higuchi, R.G., Palumbi, S.R. and Prager, E.M. (1985) Mitochondrial DNA and Two Perspectives on Evolutionary Genetics. Biological Journal of Linnean Society, 26, 375-400. https://doi.org/10.1111/j.1095-8312.1985.tb02048.x

[17] Abdul, H.A.A., Zakirah, T., Nabilah, M.A., Nur, A.A., Muhd, D.D.A., Wong, L.L., Seah, Y.G., Tun, N.A.M.J., Abol, M.A.B., Awang, A.A.K. and Shahreza, M.S. (2015) 
Mitochondrial DNA Diversity of Terubok (Tenualosa toli) from Daro and Mukah, Sarawak Inferred by Partial Cytochrome b (Cyt-b). Journal of Fisheries and Aquatic Science, 10, 92-101. https://doi.org/10.3923/jfas.2015.92.101

[18] Brown, J.R., Bechenbach, A.T. and Smith, M.J. (1993) Intraspecific DNA Sequence Variation of the Mitochondrial Control Region of White Sturgeon (Acipenser transmontanus). Molecular Biology and Evolution, 10, 326-341.

[19] Meyer, A. (1993) Evolution of Mitochondrial DNA in Fishes. In: Mochachka, P.W. and Mommsen, T.P., Eds., Biochemistry and Molecular Biology of Fishes, Elsevier Press, New York.

[20] Fajen, A. and Breden, F. (1992) Mitochondrial DNA Sequence Variation among Natural Populations of the Trinidad Gtppy, Poecilia reticulata. Evolution, 46, 1457-1465. https://doi.org/10.1111/j.1558-5646.1992.tb01136.x

[21] Abdel-Hamid, Z.G., Heba, A.M., El-Kader, A., Aboelhassan, D.M. and Mahrous, K.F. (2014) Genetic Diversity in Egyptian Tilapia Species using PCR-RFLP of D-Loop Mitochondrial DNA Gene. Research Journal of Pharmaceutical, Biological and Chemical Sciences, 5, 469-475.

[22] Agbebi, O.T., Echefu, C.J., Adeosun, I.O., Ajibade, A.H., Adegbite, E.A., Adebambo, A.O., Ilori, M.B., Durosaro, S.O. and Ajibike, A.B. (2016) Mitochondrial Diversity and Time Divergence of Commonly Cultured Cichlids in Nigeria. British Biotechnology Journal, 13, 1-7. https://doi.org/10.9734/BBJ/2016/25470

[23] Fontana, F., Conterio, F., Gandolfi, G., Tagliavini, J., Rosenthal, H., Bronzi, P. and McKenzie, D.J. (2007) Mitochondrial DNA Sequences of 6 Sturgeon Species and Phylogenetic Relationships within Acipenseridae. Journal of Applied Ichthyology, 15, 17-22.

[24] Bouza, C., Vilas, R. and Castro, J. (2008) Mitochondrial Haplotype Variability of Brown Trout Populations from North-Western Iberian Peninsula: A Secondary Contact Area between Lineages. Conservative Genetics, 9, 917-920. https://doi.org/10.1007/s10592-007-9398-8

[25] Norfatimah, M.Y., Abdulah, M.N.S., Othman, A.S., Patimah, I. and Jamsari, A.F.J. (2009) Genetic Variation of Lates Calcarifer in Peninsular Malaysia Based on the Cytochrome B Gene. Aquaculture Research, 40, 1742-1749. https://doi.org/10.1111/j.1365-2109.2009.02279.x

[26] Pereyra, S., Garcia, G., Miller, P., Oviedo, S. and Domingo, A. (2010) Low Genetic Diversity and Population Structure of the Narrownose Shark (Mustelus schmitti). Fisheries Research, 106, 468-473. https://doi.org/10.1016/j.fishres.2010.09.022

[27] Tseng, M.C., Shiao, J.C. and Hung, Y.H. (2011) Genetic Identification of Thunnus orientalis, Thunnus thynnus and Thunnus maccoyii by a Cytochrome b Gene Analysis. Environmental Biology of Fishes, 91, 103-115. https://doi.org/10.1007/s10641-010-9764-0

[28] Ajibike, A.B. (2016) Genetic Diversity of Nigerian Indigenous Chicken using Microsatellite Markers and Mitochondrial D-loopDNA Sequences. M. Agric. Dissertation, Department of Animal Breeding and Genetics, Federal University of Agriculture, Abeokuta.

[29] Hall, T.A. (1999) Bioedit: A User Friendly Biological Sequence Alignment Editor and Analysis Program for Windows 95/98/NT. Nucleic Acid Symposium Series, 41, 95-98.

[30] Tamura, K., Stecher, G., Peterson, D., Filipski, A. and Kumar, S. (2013) MEGA6: Molecular Evolutionary Genetics Analysis Version 6.0. Molecular Biology and EvoIution, 30, 2725-2729. https://doi.org/10.1093/molbev/mst197 
[31] Excoffier, L., Guillaume, L. and Stefan, S. (2005) Arlequin. Version 3.0, an Integrated Software Package for Population Genetics Data Analysis. Evolutionary Bioinformatics Online, 1, 4750. https://doi.org/10.1177/117693430500100003

[32] Habib, M., Lakra, W.S., Vindhya, M., Praveen, K., Barman, A.S., Akanksha, S., Kuldeep, K.L., Peyush, P. and Asif, A.K. (2010) Evaluation of Cytochrome b mtDNA Sequences in Genetic Diversity Studies of Channa marulius (Channidae: Perciformes). Molecular Biology Reports, 6, 41-49.

[33] Chambers, J.K., Macdonald, L.E., Sarau, H.M., Ames, R.S., Freeman, K., Foley, J.J., Zhu, Y., McLaughlin, M.M., Murdock, P., McMillan, L., Trill, J., Swift, A., Aiyar, N., Taylor, P., Vawter, L., Naheed, S., Szekeres, P., Hervieu, G., Scott, C., Watson, J.M., Murphy, A., Duzic, E., Klein, C., Bergsma, D.J., Wilson, S. and Livi, P. (2000) AG Protein-Coupled Receptor for UDP-Glucose. Journal of Biological Chemistry, 15, 10767-10771. https://doi.org/10.1074/jbc.275.15.10767

[34] Michu, E. (2007) A Short Guide to Phylogeny Reconstruction. Plant Soil and Environment, 53, 442-446.

[35] Singh, N.S., Bijay, K.B. and Anil, P.S. (2013) Population Structure of Puntius sophore Inferred from Variation in Mitochondrial. International Journal of Research in Fisheries and Aquaculture, 3, 112-115.

[36] Brahmane, M.P., Kundu, S.N., Das, M.K. and Sharma, A.P. (2013) Low Genetic Diversity and Absence of Population Differentiation of Hilsa (Tenualosa ilisha) Revealed by Mitochondrial DNA Cytochrome b Region in Ganga and Hooghly Rivers. African Journal of Biotechnology, 12, 3383-3389.

[37] Masel, J. (2011) Genetic Drift. Current Biology, 21, R837-R838. https://doi.org/10.1016/j.cub.2011.08.007

[38] Holsinger, K.E. and Bruce, S.W. (2009) Genetics in Geographically Structured Populations: Defining, Estimating and Interpreting Fixation Index (FST). Nature Reviews Genetics, 10, 639-650. https://doi.org/10.1038/nrg2611

[39] Nei, M. (1987) Molecular Evolutionary Genetics. Columbia University Press, New York.

[40] Rieseberg, L.H., Widmer, A., Arntz, A.M. and Burke, J.M. (2002) Directional Selection Is the Primary Cause of Phenotypic Diversification. Proceedings of National Academy of Science, 99, 12242-12245. https://doi.org/10.1073/pnas.192360899 